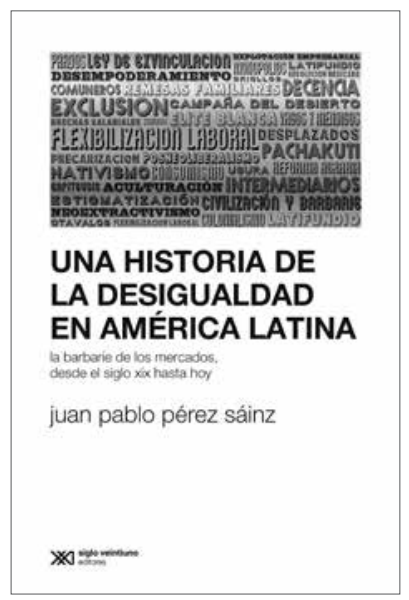

Deep Inequalities in Latin America

Vicente Moctezuma Mendoza Estancia posdoctoral, Centro de Estudios Sociológicos, El Colegio de México,

México

viamoctezuma@gmail.com

Desacatos 59 , enero-abril 2019, pp. 186-191
- Una historia de la desigualdad en

América Latina. La barbarie de los

mercados, desde el siglo xix hasta hoy

JuAn Pablo Pérez Sáinz, 2016

Siglo XXI Editores, Buenos Aires

\section{Desigualdades profundas en Latinoamérica}

\author{
VICENTE MOCTEZUMA MENDOZA
}

Y

a en el título se encuentra un indicio de lo que constituye el objetivo principal del libro: explicar a profundidad las desigualdades relativas a la captura de excedente económico en Latinoamérica. Nos remite a una de las dimensiones que constituyen esta mirada en la profundidad de la desigualdad, la que da el tiempo histórico, es decir, el reconocimiento de los procesos y transformaciones, rupturas y continuidades, que han colocado a la desigualdad como un rasgo persistente en los países de la región. Sin embargo, las claves que proporciona Pérez Sáinz y su exposición ahondan en otras dimensiones de las desigualdades. A diferencia de la perspectiva contemporánea dominante que explora la desigualdad de ingresos, el autor nos conduce a mirar la raíz: la desigualdad de poder en los mercados básicos, que permite la generación y apropiación de excedentes. Esta aproximación considera la clase social como una de las dimensiones fundamentales del (des)empoderamiento de los sujetos sociales y sus desigualdades. La mirada de Pérez Sáinz no sólo reconoce una multiplicidad de posiciones de clase, también abunda en que la clase no se considera de manera unidimensional como la única instancia de (des)empoderamiento, sino que interactúa con otras dimensiones constituyentes de los sujetos sociales 
en la producción de desigualdades en los mercados básicos. Estas dimensiones son las construcciones de "ciudadanía social", que soportan procesos de individualización, y las diferencias relativas al género, etnia/raza y territorio, como ámbitos de antagonismo. En los aspectos que acabo de referir se encuentran los planteamientos teóricos que permitirán al autor tejer su análisis sobre la desigualdad en Latinoamérica. Si esta obra es profunda en temporalidad, también lo es en el espacio, pues la región de su exposición surge como unidad de lo múltiple, en el análisis de las coincidencias, diferencias y particularidades entre sus países. Pero veamos más de cerca.

El libro Una historia de la desigualdad en América Latina está conformado por cuatro capítulos, además de la introducción y las conclusiones. Primero se expone el enfoque y los supuestos que guían el texto, y se compara con la mirada dominante actual sobre las desigualdades. Después de establecer su perspectiva teórica, Pérez Sáinz nos conduce por una historia que transita por tres momentos. El orden oligárquico, que va desde mediados del siglo XIX hasta la crisis de 1929. Esta fecha marca el comienzo del periodo denominado de modernización nacional, que representa el segundo momento. El análisis termina con el momento de modernización globalizada, que arranca en 1980 y se encuentra vigente hasta hoy, aunque existe ambigüedad sobre los significados históricos de los regímenes llamados "posneoliberales".

En el primer capítulo, "Miradas sobre las desigualdades en América Latina", el autor presenta los elementos teóricos a partir de los cuales analizará la desigualdad en los momentos históricos de los siguientes tres capítulos. Explica los elementos que conforman su marco categorial y el tratamiento conceptual sobre la desigualdad, y señala que su planteamiento se inscribe en una tradición de pensamiento, radical y crítica, que se distancia y diferencia de la perspectiva corriente sobre las desigualdades en la región y sus supuestos (neo)liberales.
Para explicar la diferencia entre éstas, las interroga, siguiendo a Norberto Bobbio, con dos preguntas fundamentales: "de qué" y "entre quiénes" es la desigualdad.

Respecto a la primera pregunta, el enfoque denominado (neo)liberal se centra en los ingresos del hogar; sin embargo, esta perspectiva presenta limitaciones. Lo que se observa con esta aproximación es la redistribución, sin voltear a ver la existencia de una distribución primaria que acaba por ser naturalizada. Además, este enfoque se dirige al resultado de la desigualdad y deja de lado las causas. Asimismo, tiene problemas metodológicos, pues en sus instrumentos de recolección de datos es poco probable que se representen los ingresos de las elites. En relación con la segunda interrogante, ¿desigualdad entre quiénes?, el sujeto que aparece en la perspectiva (neo)liberal es, de manera reduccionista, un individuo. Los intentos que han buscado complejizar esta aproximación, a partir de la identificación de "grupos", según diferentes criterios de categorización, dejan muchas dimensiones de la desigualdad en la oscuridad.

¿Cómo responde el enfoque radical/crítico que conforma este libro a esas preguntas? A la primera, ¿desigualdad de qué?, Pérez Sainz responde: de poder en los mercados básicos para generar y apropiarse del excedente económico. Con esto se busca reconocer, en el orden de las desigualdades, un conflicto y la disputa - medulares - por la distribución de excedentes, que tiene lugar en los mercados de trabajo, tierra, capital y conocimiento. Respecto a la segunda pregunta, el autor plantea: entre clases sociales, individuos y pares categoriales. Es decir, toma en consideración tres dimensiones que interactúan en la configuración de las desigualdades, presentes en la conformación de los sujetos sociales y su (des)empoderamiento:

1. Por un lado, con clase social se refiere a la dimensión del sujeto que se deriva de la posición 
relacional en la disputa por la captura de excedentes. Se apoya en Charles Tilly para formular dos mecanismos de captura de excedente. El primero nos acerca a Marx, pues se refiere a la explotación. Esta dimensión daría testimonio de la disputa entre capital y trabajo en el mercado de trabajo. En este mercado, la pugna se dirime en torno a la dicotomía trabajo/empleo - "empleo" entendido como trabajo con estatuto de garantías no mercantiles-. El segundo mecanismo, en cambio, nos acerca a Weber, pues se refiere al acaparamiento de oportunidades de acumulación, que tendría lugar en los mercados de tierra, capital y conocimiento. Las categorías para pensar en las posiciones en torno a este mercado son las de inclusión y exclusión - exclusión entendida como la monopolización u oligopolización de los recursos, que clausura para otros sujetos sociales el acceso a oportunidades de acumulación-. El reconocimiento de estos campos de disputa en la relación y constitución de las clases nos habla de su diversidad y no de un par diádico.

2. La segunda dimensión de subjetivación es la relativa a los procesos y dinámicas de individualización. En este caso, se busca reconocer "soportes" que "respaldan" a los sujetos y les permiten, o no, desencajarse o relativizar la fuerza de la posición de clase en la reproducción de las desigualdades en la captura de excedentes. Con esta idea, el autor se remite a la función del despliegue de la ciudadanía social en la construcción de un piso mínimo de igualdad entre los individuos, como lo planteó T. H. Marshall.

3. El último aspecto a considerar es lo que llama pares categoriales, con los que explica las formas de categorización social que construyen diferencias sociales y en distintas condiciones, desigualdades y antagonismos, relativas al género, etnia/raza y territorio, etc. Cuando este tipo de diferencias son también desigualdades, los sujetos subalternizados viven desventajas que se reflejan en segregación — primaria y secundaria - y discriminación, que configuran condiciones de exclusión en el acceso y la participación en los mercados básicos.

Con estos elementos analíticos, Pérez Sáinz construye Una historia de la desigualdad en América Latina. En los siguientes tres capítulos, explora, para cada momento histórico: 1) las condiciones de captura de excedente en los mercados laborales, a partir de la explotación de fuerza de trabajo; 2) las condiciones de captura de excedente mediante el acaparamiento de oportunidades en los mercados de tierra, capital y conocimiento; 3) los procesos de individualización por medio de procesos de ciudadanía que se acoplan con, o desencajan, las condiciones de (des)empoderamiento de las clases sociales, y 4) la constitución de pares categoriales, por la que los grupos sociales experimentan formas de segregación y discriminación respecto a los mercados básicos.

Con la interrelación y articulación intrincada de estas cuatro dimensiones, Pérez Sáinz arma la exposición de las configuraciones y dinámicas de desigualdad en la apropiación de excedentes económicos por las que transita Latinoamérica. Cabe destacar, empero, que el planteamiento teórico en este capítulo inicial desborda en sus alcances el objetivo regional del libro. Es decir, la riqueza de la obra radica no sólo en que nos lleva por la geografía rugosa de las desigualdades en Latinoamérica y su historia, sino que además muestra una producción teórica con potencial para mirar y analizar la desigualdad en otras geografías e historias.

El punto de arranque de esta historia, capítulo dos, es el denominado orden oligárquico. En él, Pérez Sáinz encuentra la fundación de los campos de acumulación de excedente que marcarán el desarrollo posterior. En este periodo se conservan elementos de la herencia colonial en la fundación del poder y la relación entre las elites y los grupos subalternos. 
Durante esos años hubo procesos de proletarización, en un momento en el que aún no hay un mercado laboral como tal. Sin embargo, las relaciones de trabajo que se establecen en los centros de actividades primario-exportadoras presentan una salarización deficiente, los trabajadores quedan sujetos a la relación laboral por la creación de endeudamiento y por el "sistema de enganche". Por el lado de la acumulación por acaparamiento de oportunidades, encontramos dos procesos que marcan el periodo: la privatización y mercantilización liberal de tierras de las corporaciones y la expansión de la frontera agrícola. Ambos tuvieron significados distintos en la construcción de asimetrías y la acumulación de las elites, pero el primero tuvo repercusiones profundas para los indígenas y campesinos.

Las condiciones de desempoderamiento en relación con la explotación, como en el acaparamiento de oportunidades, en parte fueron posibles por lo limitado de los procesos de individualización. Aunque Pérez Sáinz señala que existieron varias vías de configuración de la ciudadanía, la "blanqueada", la escindida y la mestiza, todas se construyeron en torno a la oposición civilización/barbarie. Las elites - hombres, blancos, propietarios, occidentales- se representaron como los civilizados y colocaron a los “otros" étnicos y "raciales" en el lugar de la barbarie. Esto nos habla de un acoplamiento tanto de la ciudadanía como de las oposiciones étnico-raciales con las dinámicas de poder de clase.

Durante el periodo de modernización nacional, capítulo tres, la configuración de las desigualdades se transformó en varias dimensiones y mostró un escenario de asimetrías menos polarizado y más diverso. El modelo de acumulación se redefinió, del énfasis en la producción primaria para exportación pasó a la producción industrial para el mercado interno. Sin embargo, esta transformación no ocurió del mismo modo en todos los países, y en muchos, el modelo previo siguió teniendo un peso importante frente a la industrialización.
Surgen mercados laborales importantes en las áreas urbanas, principalmente en las metrópolis, pero será un mercado dividido entre empleos formales y trabajos informales. ${ }^{1}$ Los primeros no sólo se salarizan efectivamente, además se benefician con el acceso a la seguridad social, en fuerte contraste con los segundos. Por otra parte, los trabajadores que no eran absorbidos en el mercado laboral tuvieron que desarrollar por cuenta propia alternativas informales en actividades de baja productividad. Estos propietarios informales, junto con medianos y pequeños, quedaban relegados de las oportunidades reales de acumulación ante las firmas oligopólicas de grandes capitales. Asimismo, durante este periodo, en el espacio rural tiene lugar una "contraofensiva" campesina, materializada en reformas agrarias. Los casos de México y Bolivia fueron los más destacados. No obstante, estos procesos no lograron revertir el poder de las elites. Pérez Sáinz explica que el resultado fue una dualización de la agricultura, con un sector mercantilizado y dinámico de propietarios capitalistas medianos y grandes, por una parte, y por la otra, un sector marginado: los campesinos, sujetos a intermediarios comerciales, con pérdida de autonomía productiva y semiproletarizados en formas precarias de trabajo.

Durante este periodo, la ciudadanía perdió su asidero en la propiedad, pero el desarrollo de la ciudadanía social se asentó en esencia en el empleo formal. De modo que las limitaciones de la formalidad se traducen en limitaciones de la ciudadanía. A esta asimetría se suma que varios servicios sociales se desarrollen sobre todo en las ciudades, como los relativos a la salud y la educación, de modo que se crean dos órdenes de desigualdad: trabajadores formales/ informales, habitantes rurales/urbanos. Pese a estas

El autor establece una diferencia analítica entre empleo y trabajo. Desde su perspectiva, no puede existir el empleo informal. 
limitaciones, esta ciudadanía fortaleció dinámicas de individualización, pues permitió que ciertos sectores subalternos experimentaran procesos de movilidad social. En este sentido, Pérez Sáinz destaca la importancia del par categorial territorial, en la oposición campo/ciudad. En esta desigualdad encontramos la explicación de la migración campesina a las ciudades. No obstante, aunque la movilidad social fue un resultado más o menos probable de la movilidad física, en muchos sentidos también fue ambiguo.

Con la crisis de la década de 1980, el modelo de acumulación se transformaría de nuevo para inaugurar el periodo de modernización globalizada, capítulo cuatro, que conforma nuestro presente. En los dos campos de desigualdades excedentes hay fuertes procesos de desempoderamiento vinculados a la implementación de políticas (neo)liberales. En lo que respecta a la explotación, hay un ataque al empleo formal. Se precarizan las relaciones salariales, lo que implica desregulación laboral, reestructuración productiva y flexibilidad laboral. Estas transformaciones derruyen, hacia abajo, las asimetrías entre lo formal e informal. El campo de acaparamiento de oportunidades también se redefine. Se constituye un mercado de capital financiero en la región, pero los pequeños productores sólo obtienen créditos en condiciones altamente onerosas. Aparecen nuevos intereses en los mercados de tierra relativos a desarrollos capitalistas de alcance global. Esto se vinculan con el agro, pero también con el turismo y el desarrollo inmobiliario, así como con el neoextractivismo en torno a las commodities. Se configura un polo globalizador que se constituye en tramas productivas fragmentadas y excluyentes. Pérez Sainz destaca que las transformaciones en el modelo de acumulación han roto formas de articulación entre los sectores excluidos o marginados y las actividades dominantes. Es en particular sensible que emergen formas disfuncionales de relación entre estos sectores excluidos y los procesos de acumulación, como lo expresan las economías ilícitas, como el narcotráfico, que tienen como recurso clave la violencia.

Todas las transformaciones anteriores han estado acompañadas de una metamorfosis profunda en la ciudadanía social. Se trata de cambios complejos, que implican la mercantilización de los servicios sociales; su redireccionamiento espacial y social; la fractura del vínculo ciudadanía/trabajo, entre otros. Sin embargo, tal vez la transformación más significativa es su despolitización. La ciudadanía ya no aparece como un medio para acceder a un piso común de derechos, y en ese sentido, como una forma de empoderamiento, evidentemente relacional, hacia mayores condiciones de igualdad. La idea de ciudadanía como fuente de empoderamiento individual desaparece ante la centralidad del consumo como espacio de realización. Por otra parte, en este periodo las luchas reivindicativas por el reconocimiento de los sujetos subalternos parecen lograr avances políticos; incluso hay discursos (neo)liberales, como el multiculturalismo en el caso de las reivindicaciones étnicas, que han buscado lograr su hegemonía. Sin embargo, el análisis muestra que este reconocimiento es reducido y limitado. Las diferencias de los pares categoriales se conservan como desigualdades en los mercados básicos. Por ejemplo, en relación con el género, aunque la segregación primaria del mercado laboral desapareció con la participación de las mujeres en la fuerza de trabajo, existe un acoplamiento importante entre el género y la dinámica de clase, en términos de segregación secundaria.

Por último, el recorrido histórico nos aproxima a los parajes de lo que se ha denominado el “posneoliberalismo”. Pérez Sáinz lo escribe así, con comillas, porque se trata de un fenómeno ambiguo, cuyas implicaciones futuras son difíciles de prever. Es un fenómeno contradictorio, tanto por las diferencias de las políticas tomadas entre los países como por sus orientaciones internas. Todos los 
regímenes comparten una continuidad en los procesos neoextractivistas, lo que los homologa al acaparamiento de oportunidades (neo)liberal; no obstante, sí han marcado ciertas rupturas, tanto en el ámbito de la explotación, con redefiniciones a favor de los trabajadores — países del Atlántico sur-, así como en el de los pares categoriales y la ciudadanía social, con reconocimiento de sectores subalternos históricamente marginados — países del grupo andino-.

Es importante señalar que la exposición histórica de Pérez Sáinz se construye con trazos finos, su historia avanza con pasos cuidadosos que se asientan con mesura. La obra es delicada en los detalles, especificidades y contrastes. Es de destacar, además, la basta literatura a partir de la cual el autor arma su argumento. Parte de la riqueza del texto es la forma visible en la que Pérez Sáinz muestra que su trabajo se edifica con el trabajo de otros colegas.
Este libro nos confronta con una historia que no es halagüeña. En la región se reproducen con persistencia asimetrías profundas: en sentidas condiciones de explotación, en un mercado laboral que no produce empleo; en el acaparamiento de oportunidades de acumulación de las elites; en desarrollos de ciudadanía social que en términos generales no han permitido transmutar el desempoderamiento en las dinámicas de clase - los desarrollos significativos de la ciudadanía social estuvieron limitados temporalmente y reducidos a un fragmento de la sociedad-, y en diferencias de género, etnia/raza y trabajo que casi no dejaron de constituir desigualdades, expresadas en segregaciones y discriminaciones en el poder de apropiación de excedentes económicos en los mercados básicos. La desigualdad persistente en Latinoamérica aparece como un reto inmenso, pero la lectura de Pérez Sáinz proporciona claves para orientar nuestra imaginación de transformación. D 